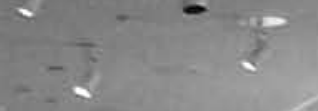

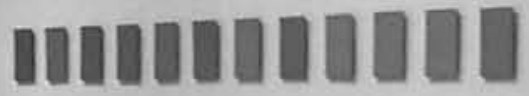

gets

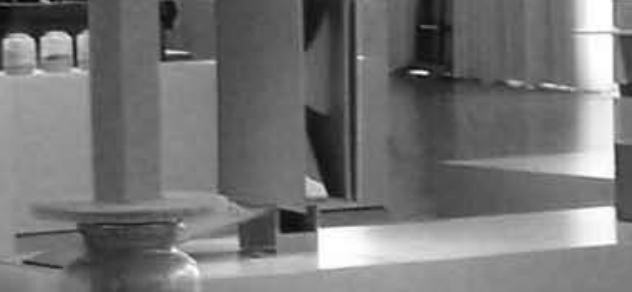

na

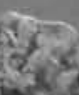

ais.s.
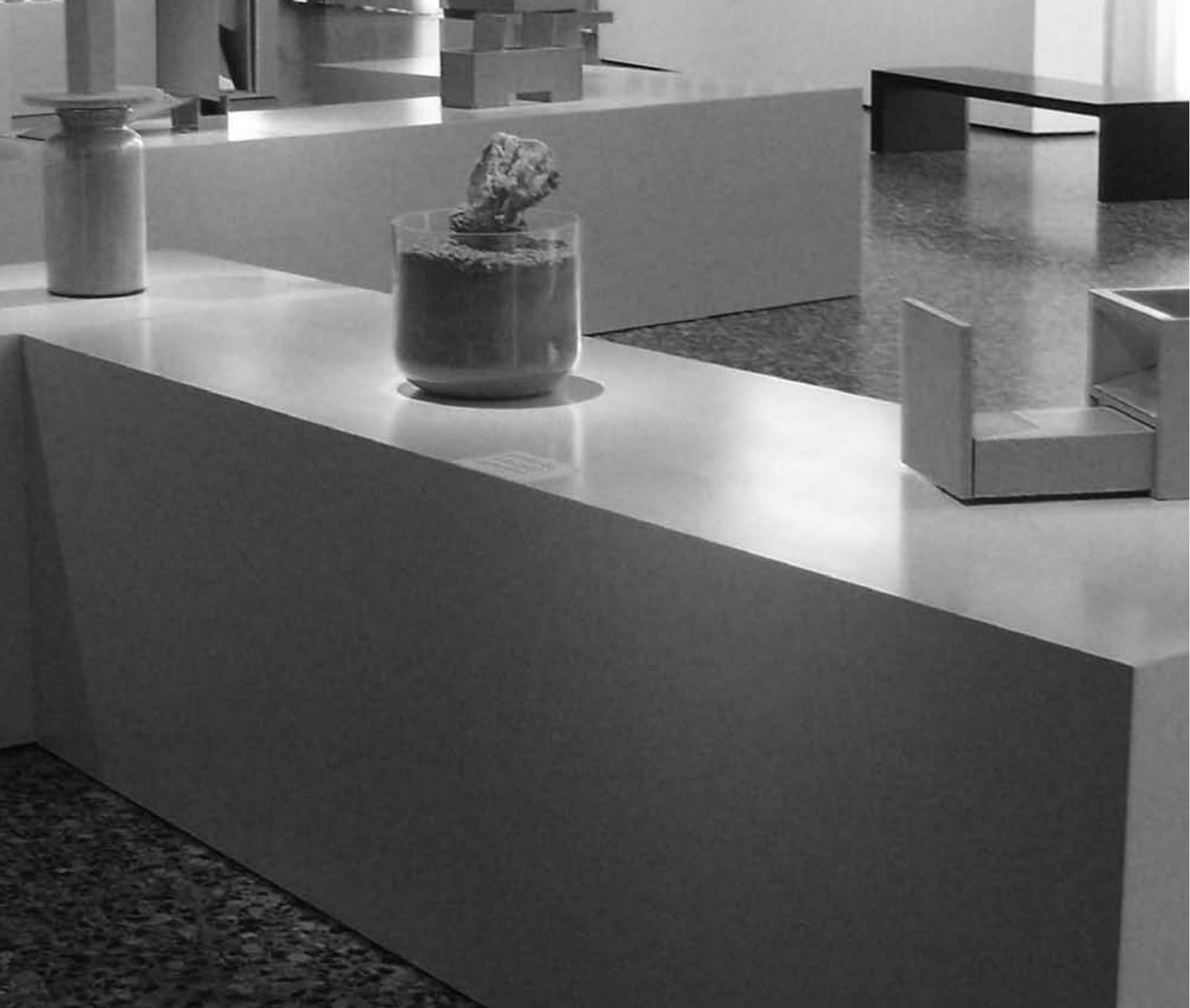


\title{
Luiz Camillo 0sorio AS CORES E OS LUGARES EM HÉLIO OITICICA: Uma leitura depois de Houston*
}

\begin{abstract}
O texto pretende discutir, a partir da recente retrospectiva de Hélio Oiticica no Museu de Belas Artes de Houston, o modo como sua poética redefine e desloca o legado moderno / construtivo a partir do momento em que assume as especificidades, por mais problemáticas que sejam, da formação cultural brasileira.
\end{abstract}

A obra de Hélio Oiticica vem ganhando nos últimos anos uma visibilidade internacional surpreendente. Depois da consagração, inicia-se agora uma nova etapa: de pesquisa, catalogação e estudo dos vários momentos de sua trajetória, procurando explorar tanto os deslocamentos criativos, a coerência interna de sua poética como a articulação com a produção internacional. O Museu de Belas-Artes de Houston, através de sua curadora Mari Carmen Ramírez, produziu uma grande exposição do artista, de caráter mais investigativo do que de divulgação, focando no desenvolvimento da cor entre os anos 1955 e 1965, ou seja, das primeiras pinturas do Grupo Frente até os "parangolés". Como a cor foi uma constante no seu percurso poético, são também apresentados alguns projetos da década seguinte: uma série dos "topological ready-made landscapes" e duas maquetes da "invenção da cor", "Magic Square Nº 1" e "Magic Square N³" (esta última realizada no Museu do Açude do Rio de Janeiro). Esta exposição viajou posteriormente para a Tate Modern.

Uma vez que a obra de Oiticica está definitivamente inserida no museu e na história da arte, é fundamental avaliarmos sua força e singularidade na cena contemporânea. Sua poética tem luz própria. Por um lado, há um diálogo intenso e riquíssimo com seus pares de geração, apropriando-se da herança moderna e contaminando-a com uma energia popular de modo a pô-la em contato (e tensão) com a vida. Seria o caso de se repensar, por exemplo, os elos e as diferenças entre o neoconcretismo, a pop (em especial com o Rauschenberg dos anos 60 e 70) e o pós-minimalismo; entre o "não-objeto", o "objeto-específico" e a "anti-forma". São características destas poéticas, guardadas as diferenças, a precarização da forma, a potencialização do corpo e a apropriação de uma multi-sensorialidade extraída da dança, do cinema, da poesia, além do samba, do rock e das drogas. Neste diálogo aberto, virão à tona diferenças extraídas de contextos culturais específicos e assim, lateralmente, a rediscussão do Brasil na obra de Oiticica. Não poderei abordar aqui todas essas questões, gostaria de concentrar no que mais me tocou depois de visitar a exposição americana: o desenvolvimento da cor em sua obra, a partir do legado e dos deslocamentos da tradição moderna, e a invenção/ 
descoberta de certa brasilidade, feita ao longo deste trajeto, por mais complicada (e perigosa) que seja esta discussão.

O Museu de Houston é um projeto de Mies van der Rohe. Suas galerias monumentais deram respiração singular à pulsação cromática da virada dos anos 50 para os 60, dos "Bilaterais" ao "Grande Núcleo". É impressionante o frescor destas peças, que vibram ensolaradas com uma energia sempre renovada. Muitas obras foram restauradas pelos técnicos do museu texano e chegam a público pela primeira vez. Logo depois dos já conhecidos "metaesquemas" há uma sala magnífica com as pinturas e "bilaterais" brancos. Jamais vistos nesta quantidade, esta "série branca" mostra o diálogo aberto de Oiticica com Malevich, em que a projeção do plano e a sensibilidade tátil do branco como cor-luz-matéria se integram e se fortalecem. A materialidade da pintura e sua energia cromática não se excluem. A cor é matéria, ela vibra com as pinceladas, e ela é pulsação luminosa, criando um campo de ação que se expande no espaço. Esta dimensão de matéria da cor, sua densidade pigmentar e seus matizes de luz surgem pelo movimento e espessura das pinceladas. Sobressai assim uma vontade 'desidealizante' de trazer a cor e a forma geométrica para sua dimensão tátil.

A passagem dos "relevos espaciais", para as "invenções", os "bólides" e o "Grande Núcleo", culminando nos "parangolés", dá toda a envergadura experimental da cor na obra de Oiticica. Entre os anos 1958 e 1964 sua poética sintetizou toda a experiência moderna da cor e a deslocou através da apropriação de novos materiais. Se em Rauschenberg podemos ver uma fusão peculiar da potência plástica de Picasso com a derrisão de Duchamp, em Oiticica, mais ou menos na mesma época, juntam-se a ambição construtiva de Mondrian com a materialidade caótica de Kurt Schwitters. Sem perda de rigor, e distante do contexto utópico do neoplasticismo, ele trouxe o ideário construtivo para o chão precário da realidade brasileira. $\mathrm{O}$ deslocamento em direção à informalidade aponta para a difícil questão de uma identidade cultural forjada fora dos parâmetros nacionalistas. Não se trata de reduzir Oiticica à questão da identidade ou da brasilidade, isso seria lamentável, mas de perceber até que ponto o atravessamento de uma realidade específica produziu um desvio singular em sua poética. Não há um abandono do diálogo "universalista", com toda uma tradição moderna indispensável, mas um reposicionamento da sua energia visual/sensorial pela contaminação de um corpo (do artista e da obra) tocado por uma situação específica de improvisação e precariedade. A equação vanguarda e subdesenvolvimento, tão cara à época, encontrou em Oiticica uma energia experimental dilacerante e radical, capaz de precarizar a forma para abri-la à processualidade e ao contato com o outro. O chão de brita do "Grande Núcleo" reverbera o diálogo tenso das "invenções" e dos "bólides".

Um dado que sobressai vendo de perto o desenvolvimento da sua obra é como ela combina a mais extrema racionalidade com uma inacreditável capacidade de nos surpreender. De dentro dos "metaesquemas" vemos germinar os 
"bilaterais" e até os "penetráveis"; entretanto, em cada etapa de sua obra irrompe uma qualidade que reinventa seus antecedentes e seus desdobramentos. Em momento algum de seu diálogo com a tradição moderna vem à tona qualquer sinal, por menor que seja, de angústia diante das influências. O passado é apropriado e se transforma em algo novo e singular. A justaposição de pinceladas de cor de Seurat, se mistura ao intenso movimento cromático de Delaunay, criando uma cor que é, em Oiticica, estrutura e tempo. Como salientou a curadora Mari Carmen Ramírez em seu ensaio no catálogo da exposição, a cor em Oiticica cruza todo o arco moderno que vai do "sentido de duração silenciosa viabilizada pela concretude física da "Série Branca", até a temporalidade metafísica que se estrutura em torno dos "relevos espaciais" e do "Núcleo", chegando, finalmente, ao tempo-real revelado pela cor-em-ação dos 'Parangolés”. ${ }^{1}$ Da concretude à ação, passando pela metafísica, a cor em Oiticica "resplandece como pele de fera", revelando uma consciência interiorizada da história da pintura que se desdobra nos mais diferentes meios e suportes, oferecendo-se integralmente ao espectador.

Para se entender o caminho experimental da cor em Oiticica, ultrapassando a relação do plano com a opticalidade, que começa nos "bólides", passa pelos "parangolés” e chega aos trabalhos finais, é importante ir além da tentação (freqüente em uma certa leitura crítica) de vê-la como mera dissolução da forma que refletiria uma relação passiva e dócil com o mundo. Para isso, há que se repensar as formas de recepção e a temporalidade da obra no desafio de dar corpo à cor diante do risco de domesticação institucional. A rediscussão da temporalidade nos leva a reavaliar o nosso próprio tempo histórico em sua sintonia e singularidade frente à modernidade central. ${ }^{2}$ Como já dito, não se trata de isolar a obra dentro de um enquadramento culturalista, fazendo da identidade cultural um obstáculo à inserção ampliada no concerto das nações modernas. Ao contrário, é justamente pela nuança de um acento particular que se pode contribuir para o alargamento das formas de vida e de subjetividade contemporâneas.

Em um texto emblemático, o artista Nuno Ramos (apesar de discordar da sua leitura devo reconhecer seu brilhantismo e agudeza) observa que "H.O. quase sempre utiliza tons e matizes, e não cores puras. Há nesta escolha, desde logo, um amor pelo intermediário, pelo que é provisório, que serve de ponto de partida, intensificando-se até o absoluto. Este assalto à idealidade pelo que é passageiro e banal - e as asperezas das madeiras de compensado são testemunhas disso - é decisivo em seu trabalho. $\mathrm{O}$ amor aos matizes e tons, à gradação de cores intermediárias, certamente provém daî”. Um pouco mais à frente, concluindo este longo parágrafo, ele acrescenta que "há uma passividade nesta expansão controlada e sem sobressaltos, uma monotonia nesta passagem das imperfeições do material ou da característica intermediária da cor à sua duração, cercando o espectador por todos os lados, que vão oferecer um solo comum nos próximos trabalhos. Nasce com os "Núcleos" este sono desobstaculizado, tão intenso quanto
1. RAMÍREZ, Mari

Carmen. The

Embodiment of Color

- from the Inside Out.

(Catálogo da Exposição

"Hélio Oiticica: the

Body of Color").

Houston: MFAH,

2007 , p. 34 [tradução

do autor].
2. Esta discussão da sintonia entre diferentes tempos históricos e tradições culturais, para além das relações de determinação e influência, surgiu-me depois da leitura da entrevista dada por Silviano Santiago a Madalena Vaz Pinto, apresentada como anexo à sua Tese de Doutoramento defendida no Departamento de Letras da PUC-RJ, sob o título Modernismo em Língua Desdobrada: Portugal e Brasil. 
3. RAMOS, Nuno. À

Espera de um Sol

Interno. Jornal do

Brasil, Rio de Janeiro,

28 jul. 2001. Caderno Idéias, p. 4-6. aconchegante, que elide o mundo e protege o sujeito, característico de todo o trabalho de Oiticica". ${ }^{3}$ Uma curiosa mistura de Antonio Candido (no método) e Paulo Prado (no temperamento) perpassa toda a análise. Gostaria de oferecer uma alternativa "tropicalista" de leitura, mais ao gosto de um Gilberto Freire, em que a suposta passividade desdobra-se em sensualidade, jamais em monotonia, e a elisão do mundo, se é que existe, longe de proteger o sujeito, vai lançá-lo ao desabrigo de uma necessidade de "sentir de todas as maneiras" que quer contraporse à lógica tediosa da eficácia. Esta seria uma aposta decadentista, não houvesse no interior de sua poética uma carga concentrada de trabalho e energia criativa, recusando todo espontaneísmo. A passividade, presente nos momentos de relaxamento e introspecção, convive com a vontade de potência, impedindo sua obra de descambar para um vitalismo autoritário ou para uma acomodação alienada. Ela é para todos e para ninguém.

Por outro lado, nossa modernização atrasada e incompleta, cheia de sobressaltos, arredia às normas de sociabilidade impessoais, traz consigo, para além dos problemas sabidos, um horizonte de inventividade comum onde precariedade e potência irmanam-se. Não se trata de valorar nossa singularidade, mas de marcar uma diferença a ser enfrentada, transformada e qualificada. A obra de Oiticica, com seu jogo de nuances e matizes cromáticos, suas arestas e dobras articulando interior e exterior, longe de se recusar a enfrentar o mundo, propõe-se a liberar uma disposição participativa que faz o movimento de mão-dupla indo da intimidade subjetiva ao compartilhamento aberto e plural. As mazelas de nossa formação patriarcal desdobram-se na cordialidade dos favores autoritários, cuja brecha positiva, todavia, seria a penetração a contrapelo de um tempero afetivo e informal nas relações sociais. A interpenetração da informalidade social e da formalidade normativa responde por parcela significativa de nossa injustiça e desigualdade aterrorizantes, assim como pela vitalidade criativa que brota da precariedade. $\mathrm{O}$ tempo das obras de Oiticica joga com essas passagens e meios-tons, ritmada pelos sobressaltos de uma energia potente e pelos recuos, cheios de frustração, das realizações adiadas. À atualidade da presença física das cores, dos materiais e das formas, agrega-se a virtualidade de possíveis desdobramentos a serem vivenciados por cada um, na hora e no lugar oportunos. É indispensável dispor-se à presença de sua obra no que ela tem de forma atual e de força virtual.

Há que se reverter o risco de domesticação institucional em disponibilidade poética, viabilizada nos encontros momentâneos com instantes de invenção. Estes momentos em que intenção e casualidade convivem, são freqüentes na obra de Oiticica: nos seus fragmentos de cor, poesia e precariedade. Isto não necessariamente se dá dentro do museu, mas pode se disponibilizar a partir daí e ficar aguardando uma atualização qualquer. Ou não. Esta exposição de Houston assim como a da Tate -- mostra que o vigor de sua obra ultrapassa toda redução a uma identidade cultural. Ela é arte em estado puro, com seus limites e surpresas, 
que se projeta em direção ao mundo e a qualquer um, tendo sido lançada, todavia, a partir de um solo cuja singularidade da formação social é simultaneamente um problema e uma possível solução. Sua obra, com seus tons e matizes incertos, consegue ser trágica e otimista, como os sambas de Noel.

${ }^{*}$ Uma primeira versão deste ensaio foi originalmente publicada no site do Canal Contemporâneo.

Luiz Camillo Osorio é doutor em Filosofia pela PUC-RJ, professor de Estética e História da Arte na UNIRIO, crítico de arte e autor dos livros: Flávio de Carvalho (Sáo Paulo: CosacENaify, 2000); Abraham Palatnik (São Paulo: CosacENaify, 2004); e Razões da Crítica (Rio de Janeiro: Zahar, 2005). É, membro do Conselho de Curadoria do MAMSP 2007/2008. 